\title{
Advanced Hypersonic Cryo-Tanks Research in CHATT
}

\author{
Martin Sippel, Alexander Kopp \\ Space Launcher Systems Analysis (SART), DLR, Bremen, Germany \\ Katalin Sinkó \\ ELTE, Budapest, Hungary \\ David Mattsson \\ Swerea SICOMP, Piteå, Sweden
}

A new EU-funded study called CHATT (Cryogenic Hypersonic Advanced Tank Technologies) has been initiated early 2012. The project CHATT is part of the European Commission's Seventh Framework Programme and run on behalf of the Commission by DLR-SART in a multinational collaboration. One of the core objectives is to investigate Carbon Fiber Reinforced Plastic (CFRP) cryogenic pressure tanks. Four different subscale CFRP-tanks are planned to be designed, manufactured, and tested.

The paper outlines the study logic of CHATT, gives a detailed presentation of the technology development tasks, and summarizes all major research results already available.

$\begin{array}{ll}\text { CAD } & \text { computer aided design } \\ \text { CFRP } & \text { Carbon Fibre Reinforced Plastic } \\ \text { CTE } & \text { Coefficient of Thermal Expansion } \\ \text { FEM } & \text { Finite Element Method } \\ \text { GLOW } & \text { Gross Lift-Off Mass } \\ \text { LH2 } & \text { Liquid Hydrogen } \\ \text { LOX } & \text { Liquid Oxygen } \\ \text { SEM } & \text { Scanning Electron Microscope } \\ \text { SME } & \text { Small Medium Enterprise } \\ \text { TPS } & \text { Thermal Protection System } \\ \text { TRL } & \text { Technology Readiness Level }\end{array}$

Abbreviations

I. Introduction

In future aviation and particularly in hypersonic systems new propellants will be used, such as liquid hydrogen, liquid methane and possibly liquid oxygen. Current EU funded studies in Europe such as FAST20XX, ATLLAS or LAPCAT investigate advanced vehicles with these fuels for passenger transport like the SpaceLiner or Lapcat A2 and some of their constituent materials and associated propulsion challenges. The question of cryogenic propellant storage inside an airliner - although of critical importance but by far not yet mastered - has not been addressed in comparable detail until the start of the CHATT project.

The need for more detailed investigations on liquid hydrogen or methane tanks in future airliners is not only urgent in future hypersonic aeronautics, but is also essential for environmental reasons in subsonic aviation. Air traffic has experienced strong growth over a long time, and it is predicted that such growth will continue at rates of $4-5 \%$ annually over the next decades. On the other hand, it is generally accepted that the emission of greenhouse gases, most notably of carbon dioxide $\left(\mathrm{CO}_{2}\right)$, resulting from human's activities, cannot be allowed to continue increasing if adverse global climate change is to be avoided. Liquid hydrogen, produced on the basis of renewable energy, is the only known new fuel meeting the requirements.

Cryogenic fuel propulsion is already operational in advanced launcher systems and Europe has some expertise with the Ariane rocket. However, the airliner systems will require more complex technology (compared to those existing in today's launchers like Ariane 5), such as ultra-light-weight and reusable propellant tank systems. The propellant tank technologies are critical for the vehicle operations, cost and safety. 
New materials and design concepts are required, such as fibre composites, in order to reduce the tank weight and to increase the structural performance. This is particularly important if the tank has load carrying functions. Different to current rocket launch systems, the durability through hundreds or even thousands of flight cycles must be assured. Tank liners are another essential element of a tank design in order to assure the material compatibility over long durations. Embedded structural health monitoring systems are required to assure acceptable turn-around time between flights, to optimize the service and maintenance effort and to allow low design margins without lowering overall safety. Propellant management is imperative for achieving reliable and efficient vehicle operation. The sloshing of cryogenic fluids close to their boiling conditions in tanks of horizontal take-off vehicles is not yet mastered.

\section{Organizational structure}

The project CHATT is part of the European Commission's Seventh Framework Programme (FP7) and run on behalf of the Commission by DLR-SART in a multinational collaboration. One of the core objectives is to investigate Carbon Fiber Reinforced Plastic (CFRP) cryogenic pressure tanks. Four different subscale CFRP-tanks are planned to be designed, manufactured, and tested. The total budget is exceeding 4.2 M€ with an EU contribution of almost 3.3 M€ [1]. The project started in January 2012 and runs for 42 months with a scheduled end in June 2015.

Eleven different partners from seven European countries are participating in CHATT. A list of all involved partners with their country of origin and full organization name is presented in Table 1.

Table 1: List of CHATT partners

\begin{tabular}{|l|l|l|}
\hline Short Name & Country & Participant organization name \\
\hline DLR & Germany & Deutsches Zentrum für Luft- und Raumfahrt \\
\hline FOI & Sweden & Totalförsvarets Forskningsinstitut \\
\hline SICOMP & Sweden & Swerea Sicomp \\
\hline ULB & Belgium & Université Libre de Bruxelles \\
\hline ORB & Austria & Orbspace \\
\hline ELTE & Hungary & Loránd Eötvös University (ELTE) Budapest \\
\hline TUD & Netherlands & Technical University Delft \\
\hline ECM & Germany & Engineered Ceramic Materials GmbH \\
\hline CENAERO & Belgium & Centre de Recherche en Aéronautique ASBL \\
\hline GDL & UK & Gas-Dynamics Limited \\
\hline ALE & Netherlands & Advanced Lightweight Engineering \\
\hline
\end{tabular}

The organizational breakdown of the CHATT project is very balanced concerning the type of the partners and is as follows:

- SME: $\quad 5$ (ORB, ECM, CENAERO, GDL, ALE)

- Research institutes: 3 (DLR, FOI, SICOMP)

- Universities: 3 (ULB, ELTE, TUD)

Large industrial companies are not involved in CHATT. All partners receive a $75 \%$ funding by the EU-commission for their research activities. $25 \%$ are funded by internal contribution of each partner. The financial breakdown per country is shown in Figure 1. 
The project is managed by DLR-SART with the support of Work-Package leaders based in partner organizations. Regular meetings are essential for the technical exchange. A total of 6 progress meeting (PM) are planned (every 6-8 months) with the first PM already held in Budapest in July 2012. A PM is a 2-3 days event. Ad-hoc meetings on WP level may be organized if necessary.

\title{
Financial Distribution Breakdown
}

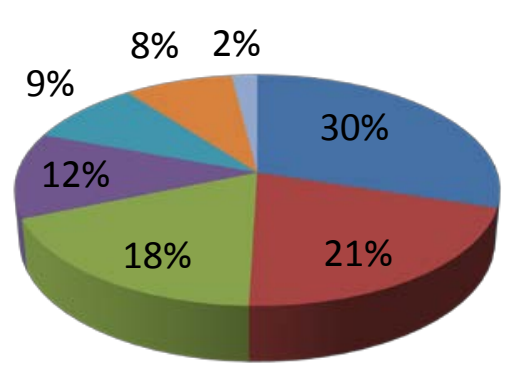

\author{
Germany \\ Sweden \\ Belgium \\ Netherlands \\ UK \\ Austria \\ Hungary
}

\section{Figure 1: Financial Distribution Breakdown in CHATT per country}

Data exchange is organized via a secure electronic team-site (Figure 2), which features a calendar with an announcements \& task list, a library section with folders for deliverables, reports, PM presentations, other publications or literature, templates $\&$ general documents, as well as partner's contact data.

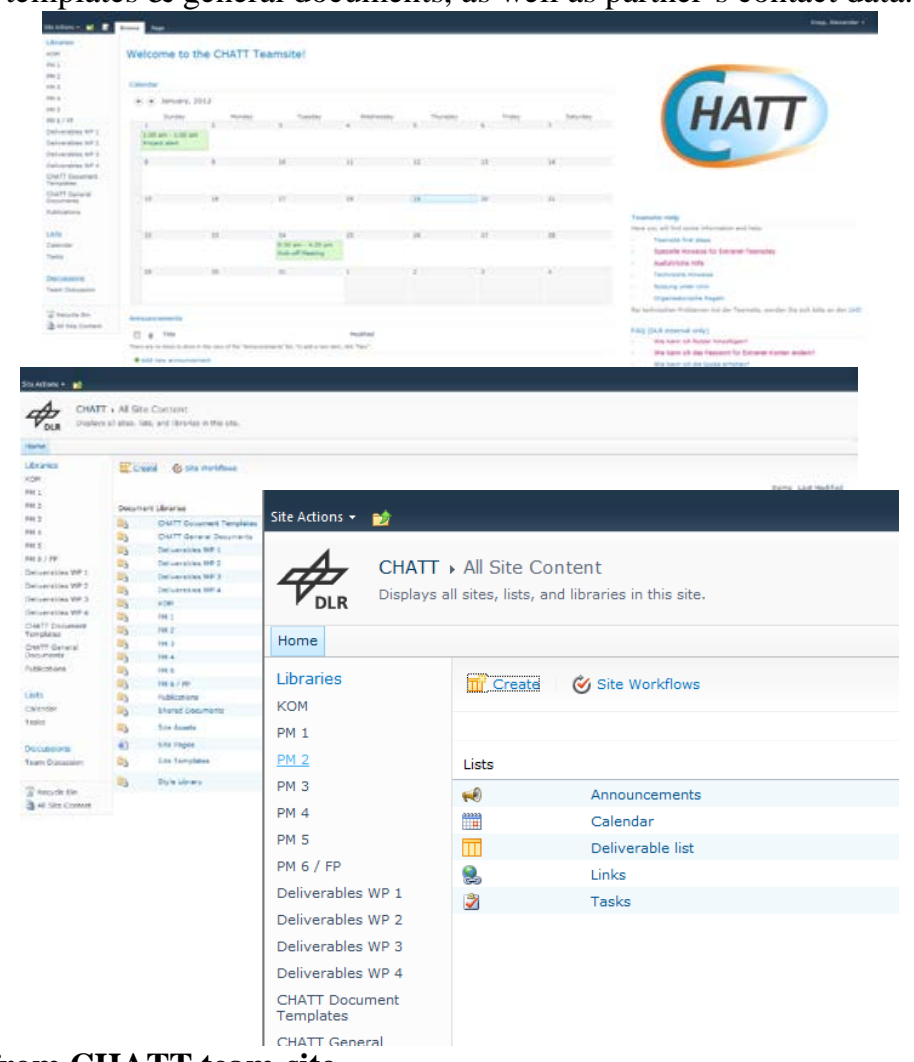

Figure 2: Screen-shots from CHATT team-site

A dedicated public internet site featuring general information about CHATT as well as providing all published papers for download is also available at http://www.chatt.aero .

\section{Research activities}

The intended research in CHATT will increase the knowledge within Europe to a practical cryogenic tank demonstrator level for future aerospace reusable lightweight composite cryogenic structures. The advantages and 
disadvantages of using liner/linerless tank designs will be investigated as well as issues related to the realization of more complex geometrical tank shapes.

The project is broken down into three main technical activities (Workpackages WP2 to WP4), which have a close interaction as shown in Figure 3.

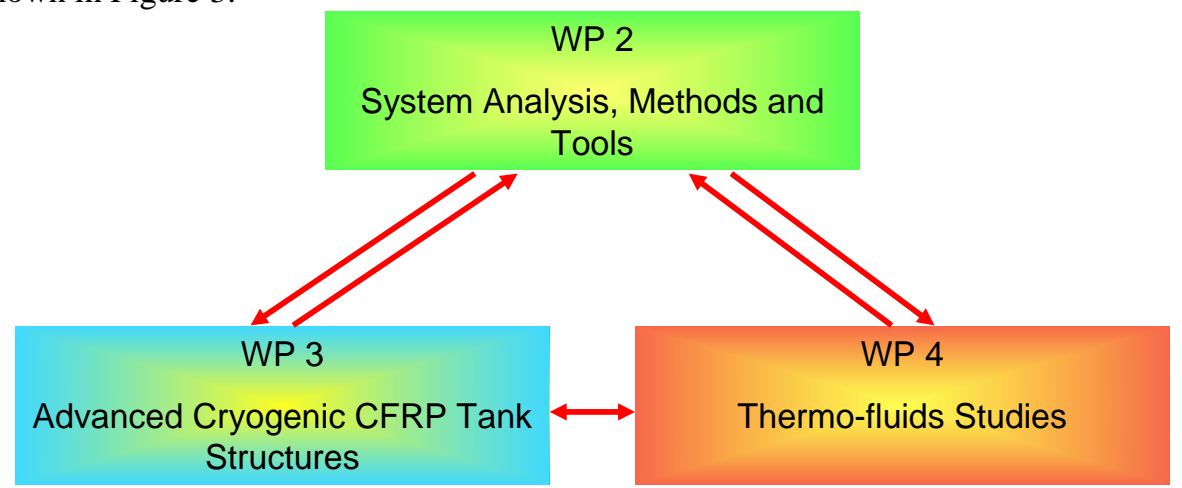

Figure 3: Interaction of different workpackages in CHATT study [1]

A central, steering role is applied to WP2 focusing on system requirements of advanced passenger airplanes, the development, test and implementation of engineering methods and tools. The two remaining workpackages WP3 and WP4 are dedicated to fundamental research with special focus on manufacturing and testing of fully integrated subscale hardware samples. Both WPs are serving as modules supporting the vehicle design and the verification of fast engineering methods.

Four different subscale CFRP-tanks are planned to be designed, manufactured, and tested under mechanical and thermal loads within the scope of the CHATT project. The challenge in developing a cryogenic CFRP tank is finding a solution for the problems caused by differences in thermal expansion coefficients (CTE) on a microscopic scale. If a liner is required, there is also the challenge to overcome the differences in CTE of the liner with respect to the structural shell.

All advanced cryogenic tank technologies to be investigated within CHATT are driven by system demands of future hypersonic passenger configurations. Such vehicles are under study in other EU-funded cooperative projects LAPCAT and FAST20XX [10]: LAPCAT A2, LAPCAT M8, and the SpaceLiner. Thus, the vehicles have already reached a certain level of maturity in their respective propulsion demands and overall size. However, the cryogenic tank systems have not been studied in any detail and major challenges concerning tank weight, sloshing, and insulation have not yet been addressed.

One supersonic transport aircraft being researched as part of CHATT is the A2 Mach 5 Civil Transport of Reaction Engines Limited (Figure 4). This aircraft design should be capable of flying from Europe to Australia in 5 hours. The vehicle is intended to have about 20000 kilometers range calling for the use of liquid hydrogen as a fuel which also can be used to cool the vehicle and the air entering the engines via a precooler.

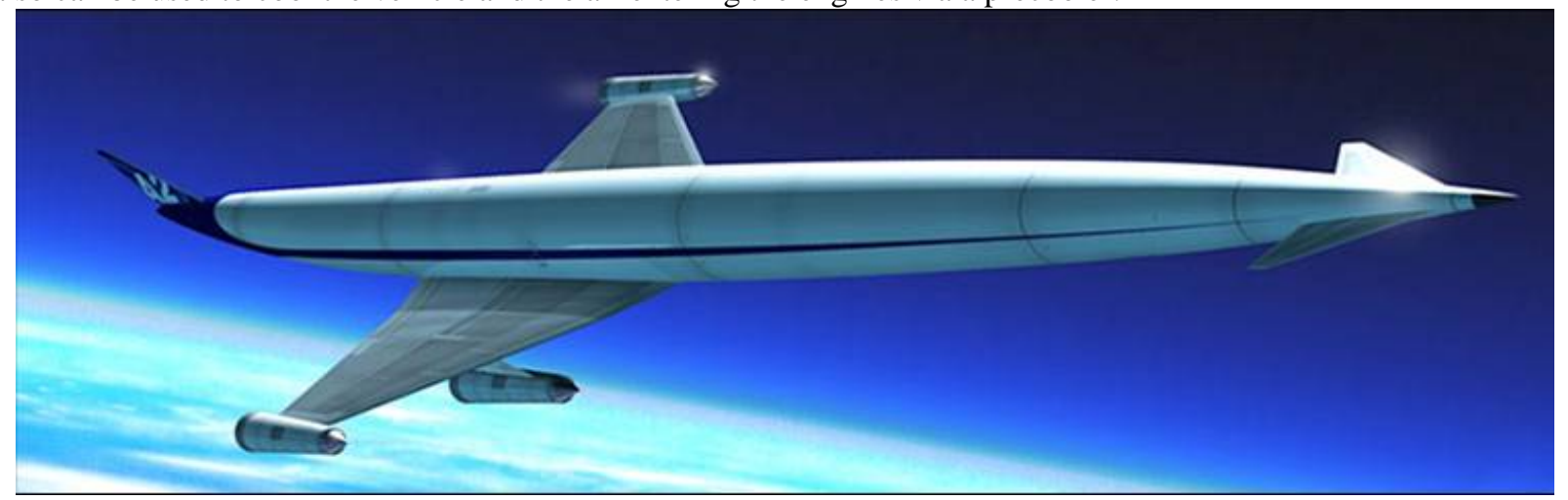

Figure 4: LAPCAT A2 hypersonic Mach 5 Civil Transport [2] 
To attain and maintain such high speeds, Reaction Engines Limited would need to develop its newly designed concept engine called the Scimitar, which exploits the thermodynamic properties of liquid hydrogen. The airframe configuration is an efficient structural shape with circular cross section hydrogen tankage and uninterrupted carrythrough wing spars. The vehicle is sized to carry 300 passengers.

An interesting alternative to air-breathing hypersonic passenger airliners in the field of future high-speed intercontinental passenger transport vehicles might be a rocket-propelled, suborbital craft. Such a new kind of 'space tourism' based on a two stage RLV has been proposed by DLR under the name SpaceLiner [3, 4, 6, 9] and is shown in Figure 5. Ultra long-haul distances like Europe - Australia could be flown in 90 minutes. Another interesting intercontinental destination between Europe and North-West America could be reduced to flight times of about one hour.

The functionality of rocket propulsion is a proven technology since decades and their performance characteristics are well known. Furthermore, a rocket powered RLV-concept like the SpaceLiner is more attractive because the flight durations are two to three times lower than those of even the most advanced airbreathing systems. In contrast to the first generation of SST, a substantial advantage in travel times and hence improved business case can be expected.

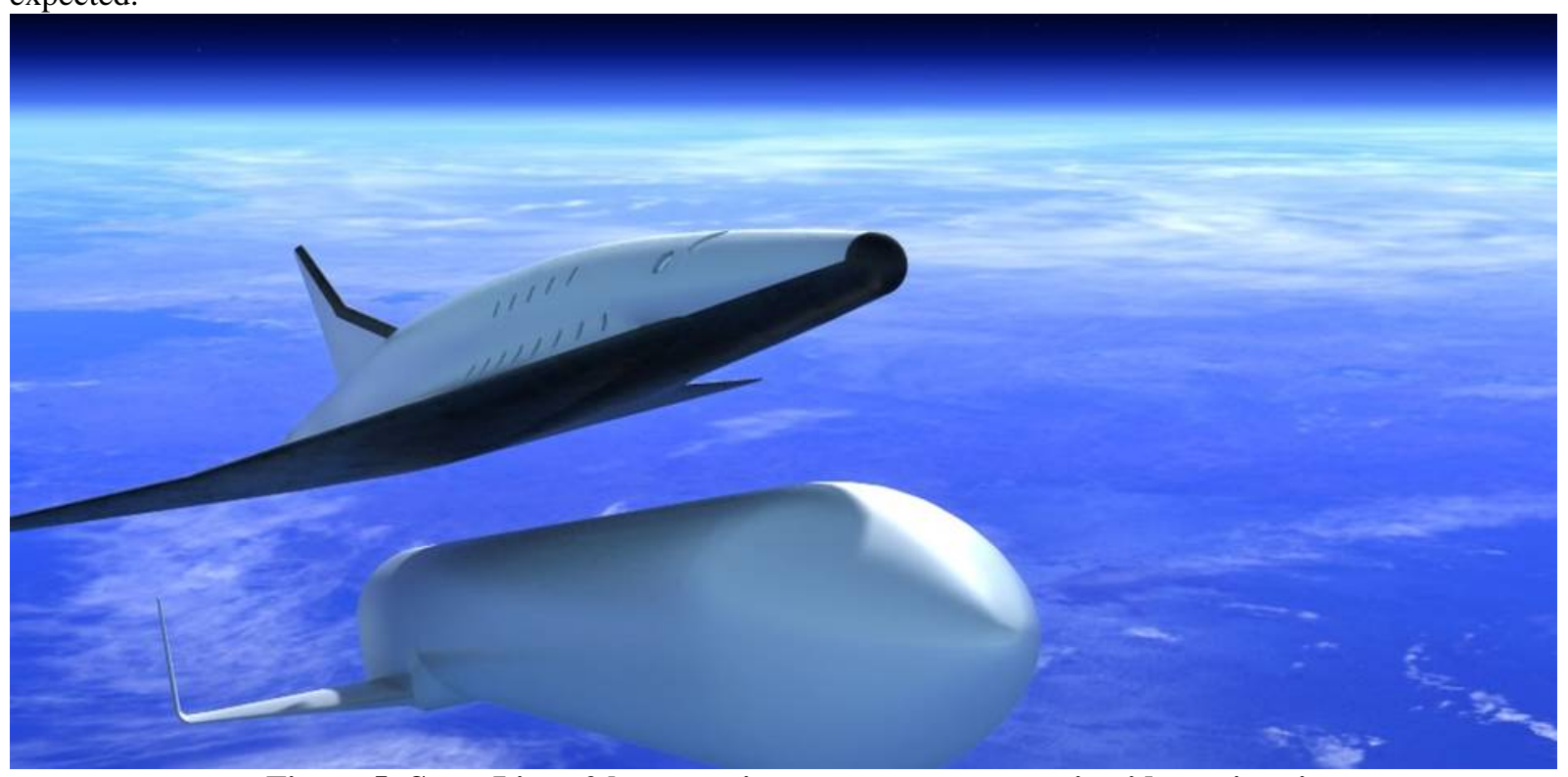

Figure 5: SpaceLiner 2 hypersonic passenger transport in video animation

Propellant management is imperative to achieve reliable and efficient vehicle operation. It is therefore the third pillar of the CHATT study and covers tank pressurization, fuel location/retention, and sloshing in horizontal tanks. Apart from thermal aspects, sloshing of cryogenic fluids within the tanks can have a significant impact on flight operation as the liquid excited through vehicle movements may travel distances of considerable lengths compared to the overall size of the aircraft. The vehicle may consequently experience a noticeable shift in its center of gravity and hence its controllability is put into question.

Counter-measures such as anti-sloshing devices and tank design are susceptible to reduce these effects but will come at the cost of increased mass and production effort. As a consequence a trade-off between hardware design and flight control development in order to minimize the impact of propellant sloshing is an important step in the design phase of a hypersonic vehicle. The CHATT study will focus on establishing engineering models for sloshing verified by numerical calculations and experiments. These models will then be applied to flight control simulations of the reference vehicle concepts allowing an evaluation of their overall feasibility.

The propellant crossfeed between the two rocket-powered stages of the SpaceLiner enables a significant performance improvement. However, crossfeed between operational stages is highly innovative and has never been demonstrated in flight. A simulation of the steady and transient behavior in the propellant feed-system will be 
performed along the powered flight, performance and critical points will be evaluated, and recommendations will be derived.

Heat-exchangers are one of the most essential elements of a tank pressurization system. Two different types of ceramic heat-exchangers will therefore be looked at in CHATT. In addition to fuel tank pressurization, also oxygen tank pressurization will receive a strong focus, because it is required by systems which partially or fully rely on rocket propulsion like the SpaceLiner.

The air-conditioning system for the hypersonic vehicles investigated in CHATT will be based on a system in which bleed air from the intake exhaust is cooled using cryogenic fuel and then compressed to achieve the conditions required for the cabin air supply. Power for the compressor and other cabin sources is provided by a Rankine cycle on the cryogenic fuel. The ultimate objective is to develop a Rankine cycle cabin air-conditioning system, utilizing a cryogenic working fluid. The absorbed heat will be used to generate electrical and mechanical power. A detailed design will be developed and a small scale $(15 \mathrm{~kW})$ prototype turbine will be constructed and tested.

In Table 2 a list of individual items describes in short the objectives in technology development along with their present TRL. CHATT will provide the opportunity to increase the level towards the TRL-scale shown in the right column.

Table 2: Progress of proposed technologies in terms of TRL-grading

\begin{tabular}{|l|c|c|}
\hline Technology description & $\begin{array}{c}\text { Present } \\
\text { TRL }\end{array}$ & $\begin{array}{c}\text { Envisaged } \\
\text { TRL }\end{array}$ \\
\hline \hline Flight control development sloshing case & 1 & $2 / 3$ \\
\hline Aeroelastic modelisation of tanks & 2 & 3 \\
\hline Tank preliminary design model & 2 & 5 \\
\hline Tank System Engineering Methods & 3 & 5 \\
\hline Liner Design & 3 & 4 \\
\hline Tank Design with Liner & 3 & 4 \\
\hline Cryogenic dry wounded carbon fiber pressure vessel & 2 & 4 \\
\hline Tank Design without Liner & 3 & 4 \\
\hline Tank Design with Complex Shape & 3 & 4 \\
\hline Testing and Health Monitoring & 4 & 5 \\
\hline Tank insulation (Aerogels) & 2 & 3 \\
\hline High Order Methods for Sloshing Simulation & 2 & 5 \\
\hline Sloshing Tests and Modeling & 2 & 4 \\
\hline CMC Heat exchanger technologies & 1 & 3 \\
\hline Cryogenic Rankine Cycle & 2 & 4 \\
\hline
\end{tabular}

\section{Early Research Results}

The CHATT-study officially started on January, $1^{\text {st }}$, 2012. After approximately eight months of work some results of the research are already available. However, major hardware has neither been manufactured nor tested. The following sections give an overview on requirements and loads definition and preparatory work.

\section{A. Mission and loads of system concepts}

The vehicle reference design loads and conditions have been defined for three reference vehicles representing three different concepts of hypersonic transportation vehicles. The focus is on the two hypersonic cruising passenger aircraft studied in the FP7 project LAPCAT II, namely the Mach 5 cruiser called A2 (Figure 4) and the Mach 8 cruiser with SCRAM-propulsion and on the rocket-powered SpaceLiner passenger transportation system (Figure 5) currently under investigation in the FP7 project FAST20XX. Mechanical and thermal reference load environments for the tank designs of these concepts are listed in Table 3.

The most striking difference in load history between the concepts is the operation time of the cryogenic tanks. The rocket-powered SpaceLiner has less than $5 \%$ of the air-breathing concepts storage time for cryogenic fluids. Thus, the thermal insulation can be significantly reduced compared to horizontal take-off vehicles. 
Table 3: Comparison of mission loads on cryogenic tanks of the reference system concepts

\begin{tabular}{|l|c|c|c|}
\hline & $\begin{array}{c}\text { Horizontal-Take-off } \\
\text { Mach 5 cruise } \\
\text { airplane A2 }\end{array}$ & $\begin{array}{c}\text { Horizontal-Take-off } \\
\text { Mach 8 cruise } \\
\text { airplane M8 }\end{array}$ & $\begin{array}{c}\text { Vertical Lift-off } \\
\text { Hypersonic } \\
\text { Passenger transport } \\
\text { SpaceLiner }\end{array}$ \\
\hline Total flight duration [ s ] & 16500 & 11000 & 5200 \\
\hline Operation duration of cryo-tanks [ s ] & 16500 & 8200 & 480 \\
\hline Number of design cycles & $1000+$ & $1000+$ & 150 \\
\hline Maximum axial acceleration $\mathrm{n}_{\mathrm{x}}\left[\mathrm{g}_{0}\right]$ & $<1$ & $<1$ & 2.5 \\
\hline Maximum normal acceleration $\mathrm{n}_{\mathrm{z}}\left[\mathrm{g}_{0}\right]$ & 2.5 & 2.5 & 2.5 \\
\hline Maximum tank pressure [ kPa ] & 300 ? & 300 & 250 \\
\hline Fluid temperature LH2 [ K ] & 21 & 21 & 21 \\
\hline Maximum outer tank wall temperature [ K ] & 600 & 800 & 480 \\
\hline
\end{tabular}

While the Mach 5 A2 and the SpaceLiner both are using relatively conventional cylindrical or conical tanks, the LAPCAT II Mach 8 cruiser of ESTEC tries using as much internal volume of its waverider shape as possible. A complex multi-lobe tank design with large wall surface area per volume has been proposed as the technical solution (Figure 6).

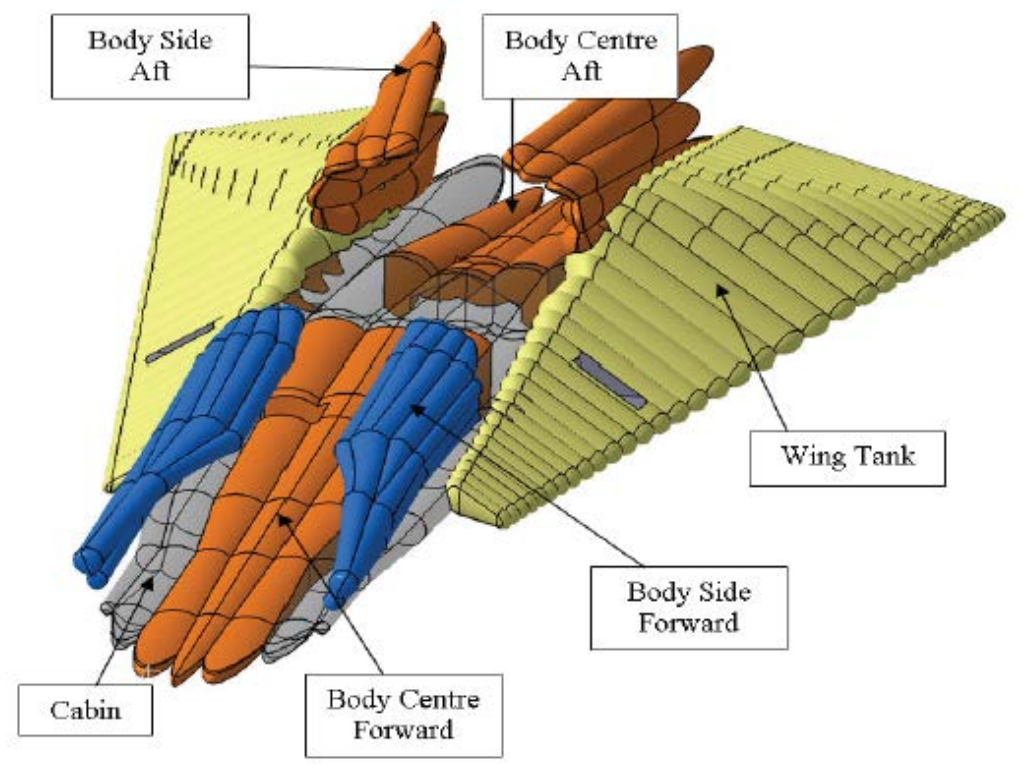

Figure 6: Multi-lobe tank arrangement proposed for LAPCAT II Mach 8 cruiser

\section{B. CFRP tank structures}

Fibre reinforced materials are structurally the most efficient material for pressure vessels because there is the possibility to direct the right amount of fibers according to the orientation and the magnitude of the principal stresses, which makes it an iso-tensoid structure. Carbon fibers are currently known to have the highest specific strength and stiffness which makes it the material of choice when it comes to aerospace structures. For advanced tank wall materials the high specific strength at cryogenic temperatures is one of the most essential parameters. Figure 7 is demonstrating the high interest of a CFRP design. Fracture toughness and stiffness are also important properties. Depending on the type of application, different designs may be favourable and tanks may thus be built as single-, double-wall or sandwich structures.

Within the category of tanks with liner there are two subgroups, namely wet wound tanks and dry wound tanks. The first concept is the classical one. Several institutes have worked out this classical concept into a fully matured product and have published papers on their development process and results. The second concept is patented by ALE, and no standard solutions for the development of this concept for cryogenic propellant storage can be found in the literature [11]. 


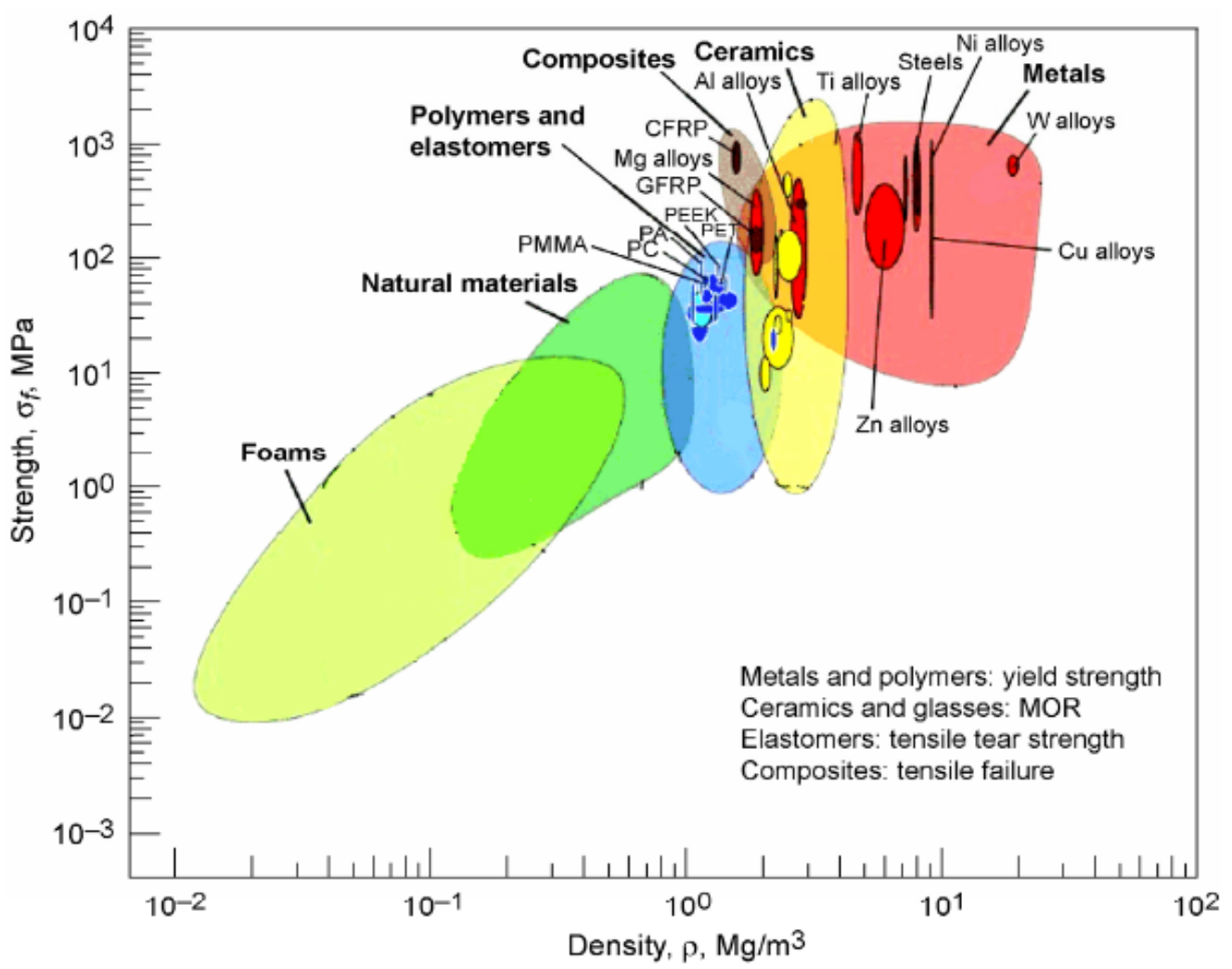

Figure 7: Strength versus mass density for various engineering materials [5]

A linerless tank has the advantage over a tank with liner that mass, cost and production time can be reduced. This however means that both the load carrying task, as well as the task of holding the propellant inside the tank should be done by only the composite shell [11]. The X-33 demonstrator tank consisted of a multilobed and linerless configuration with integrally bonded, woven composite joints. However, that tank failed in 1999 during ground testing due to polymer matrix micro-cracking and leakage into the sandwich core material causing delamination between the core and the inner composite skin. The tank showed leakage with subsequent damage, so-called “cryopumping”.

Northrop Grumman and NASA later completed within the NGLT project a nine-month test series to demonstrate a cylindrical composite cryogenic tank. The problems that brought the X-33 to a halt were proven to be solved in 40 load cycles performed without failure. The integral tank, utilizing an impermeable barrier film between the inner tank wall and the honeycomb [5] was filled with LH2 and pressurized. The program highlighted the need to improve the permeation resistance with liner materials.

The advantage of a tank with liner is that the task of holding the propellant inside the tank and the task of carrying the loads are done by two different parts. The liner can be designed to prevent permeation and to be chemical compatible with the propellant without worrying about carrying the loads. The composite can be designed to only hold the load, without worrying about permeation. The disadvantages of the liner tank concept are the increased mass, cost and fabrication time. Moreover a mismatch between the CTEs of the liner and the composite can result in separation of the liner and interlaminar debonding in case inappropriate glue is used in an inappropriate way [11]. For low temperature applications the increasing brittleness of the liner has to be considered to ensure gas-tightness. For typical carbon epoxy composites the vessel structure itself is not critical under cryogenic boundary conditions.

Four different subscale tank concepts will be designed, manufactured and tested within CHATT:

- Cylindrical tank with liner by DLR

- Dry wound cylindrical tank with liner

by ALE

- Cylindrical tank without liner

- Complex shape tank by FOI/SCICOMP by TUD 
At DLR-Braunschweig three different tank design variants have been in the discussion and have been analysed in pre-production runs:

- Two caps with a cylindrical part. Here, the tank is cut after winding in half and coated. Thereafter the tank is stuck together by a bandage (Figure 8 ).

- Closed tank with an inner skin made of PE

- An inner tank raw body made of a soluble material which is to be removed after winding

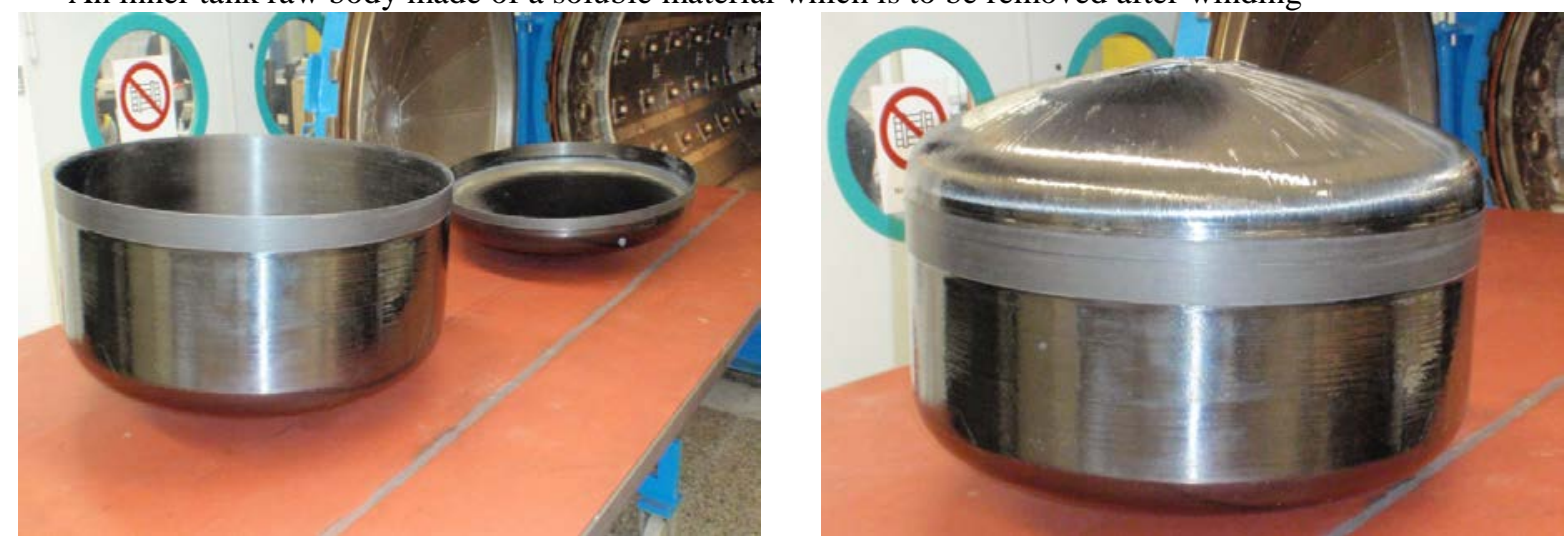

Figure 8: Tank with bandage in test production run at DLR

The test tank of the first option was built with a body made of Polystyrene, a soluble material, with good results. The tank was then cut in the middle and afterwards glued together with a bandage (Figure 8). The flange connection will be worked out in detail, specifically the connection of the flange to the tank. Other next steps are the specification of the PE liner and checking the manufacturability.

A polymer liner design has been performed by Swerea-Sicomp [12]. Several liner materials will be evaluated throughout the project using both numerical analyses and mechanical testing. Two main candidates are however identified from a literature review [12] as the most promising materials which can also be mixed with nano-particles if it is necessary to match the CTE to the base laminate to decrease thermal stresses:

- Liquid Crystal Polymer (LCP). In particular the Vectran ${ }^{\circledR}$ LCP fiber

- Perfluoroalkoxy (PFA), in particular the Teflon ${ }^{\circledR}$ PFA TE-7224

The adhesive EA9394 is chosen as the baseline for the joining of the liner material to the base laminate. The base laminate will consist of the following constituents:

- Toray T700S carbon fibers

- Toray $250^{\circ} \mathrm{F}$ epoxy resin

Three cross-ply lay-ups with different thickness of the $90^{\circ}$ layer were selected for numerical analysis of suitable base laminate. Mechanical loading as well as thermal loading of $+150^{\circ} \mathrm{C},+22^{\circ} \mathrm{C}$ and $-150^{\circ} \mathrm{C}$ was considered in the calculations. It was shown that at low temperatures, such as $-150^{\circ} \mathrm{C}$, much higher tensile stresses transverse to the fibers develop compared to elevated temperatures such as $+150^{\circ} \mathrm{C}$. Therefore, micro-cracking at lower temperatures will occur at lower mechanical load levels [12].

An advanced FEM analysis was performed to calculate manufacturing induced residual stresses in laminates showing comparable results with laminate scale calculations. Figure 9 shows a cross section in the middle of the model after curing and demoulding. It is clear that there are tensile stresses in the $90^{\circ}$ layers at the surfaces and compression stresses in the $0^{\circ}$ layer [12].

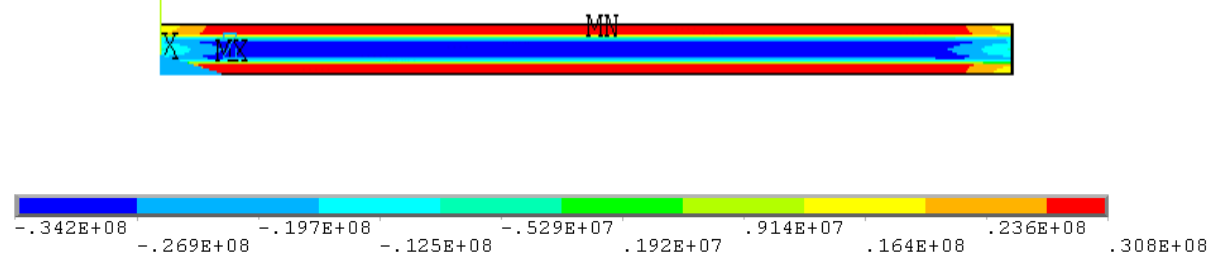

Figure 9: Stresses $[\mathrm{Pa}]$ in the $[\mathbf{9 0 / 0}]_{\mathrm{S}}$ layup obtained from FEM 
Micro-cracking behavior of laminates without the liner was analyzed using maximal stress criterion as well as Weibull analysis. Results showed that higher crack density corresponds to laminates with thinner $90^{\circ}$ layers for a fixed strain level. Also it was shown that crack evolution proceeds much faster at low temperatures such as $-150^{\circ} \mathrm{C}$ [12].

Future work in CHATT will contain an evaluation of the best polymer liner material both with and without the base laminate using mechanical and thermal loads considering static and fatigue load spectra. The test specimens will be exposed to strain levels resulting both in zero damage and also strain levels resulting in micro-cracks in the base laminate.

\section{Propellant crossfeed}

Crossfeeding is the propellant transfer from one tank to another tank or stage during flight. The fundamental challenge of all launch vehicles with reaction engines is their high mass and hence thrust requirement at lift-off and their relatively low mass and lower thrust requirement at burn out. Throttling of the engines is a technical solution, however, related to some drawbacks: Its realization is relatively complicated and, even worse, a large number of engines results in a high vehicle burn-out mass reducing the achievable $\Delta$-v. Parallel staging reduces engine requirements but would result in partially empty tanks at staging. Crossfeeding of the propellant from the first to the second stage during mated flight allows for better performance of the whole vehicle and is therefore used for the SpaceLiner.

The potential crossfeeding architectures are line-to-line and tank-to-tank. Both options are investigated for the propellant cross-feed between the two SpaceLiner stages. The overall feed line architecture has been defined and is simulated in steady flow behavior. Figure 10 shows the tank and propellant feed system arrangement with the booster in the lower part and the passenger stage or orbiter in the upper section. The aft end of the configuration with the engine propellant distribution manifolds is at left.

The preliminary technical selection on the LOX-side is the tank to tank connection which allows feeding the orbiter engines always from the orbiter tank. This approach minimizes any disturbances at stage separation. Due to a significant height difference of the two LOX-tanks, gravity and acceleration will automatically push the liquid oxygen from the booster to the orbiter. On the LH2-side a line to line crossfeed is the likely selection. As can be seen from Figure 10 some height is available from the booster's LH2 tank to the orbiter's engines and a large cross section line is selected to minimize losses. Depending on the actual pressure losses, the engine NPSP requirement might be fulfilled. The need of check-valves or additional feedline pumps is still to be investigated. Future work will also include transient simulations of the crossfeeding process taking into account throttling, the engine shut-down, and the crossfeed valve closure prior to separation.

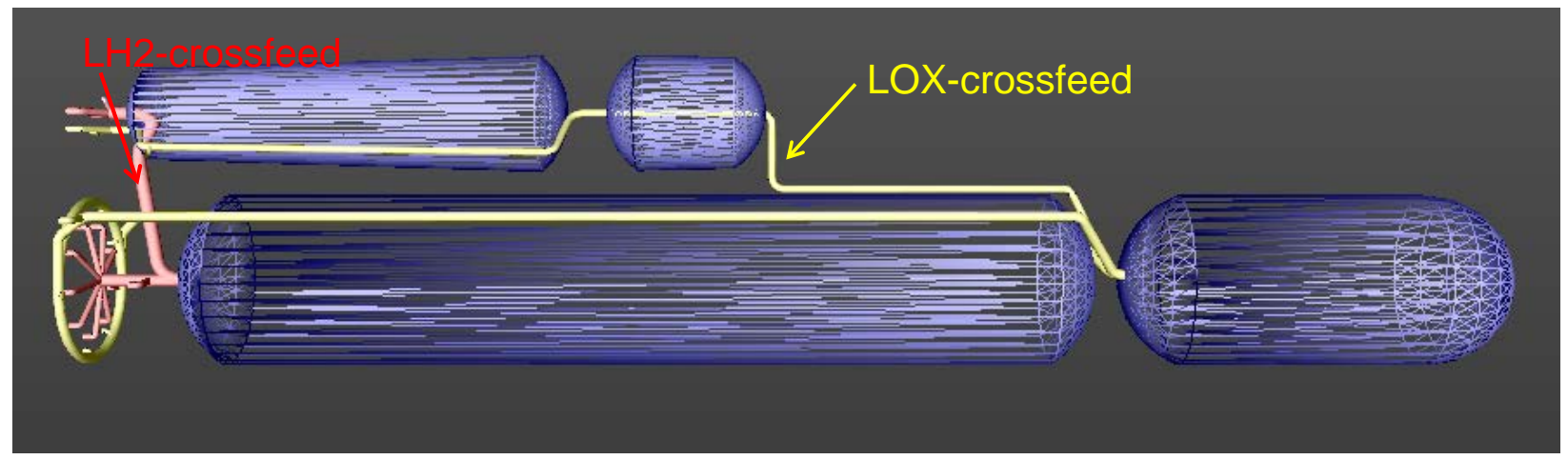

Figure 10: SpaceLiner 7 propellant feed system

\section{Aerogels for insulation}

An appropriate thermal insulation system is critical for LH2 storage tanks, particularly for long-duration applications. Thermal insulation of cryogenic tanks is more demanding than in launcher applications because typical operation times are hours instead of minutes (compare Table 3). An efficient and lightweight insulation system will minimize the boiloff of LH2 while adding minimum mass to the overall tank structure. Therefore, a low thermal conductivity $k$ and low material density is desirable (lower left corner of Figure 11, left). Further, for a given wall 
thickness, it is desirable to minimize the thermal diffusivity a (maximize specific heat) in order to maximize the time it takes to reach a steady-state condition especially for short-duration applications. According to [5] the ratio $\mathrm{k} / \mathrm{a}^{1 / 2}$ should be minimized for insulation materials. As shown in Figure 11 aerogels are promising, innovative materials for these optimization requirements.
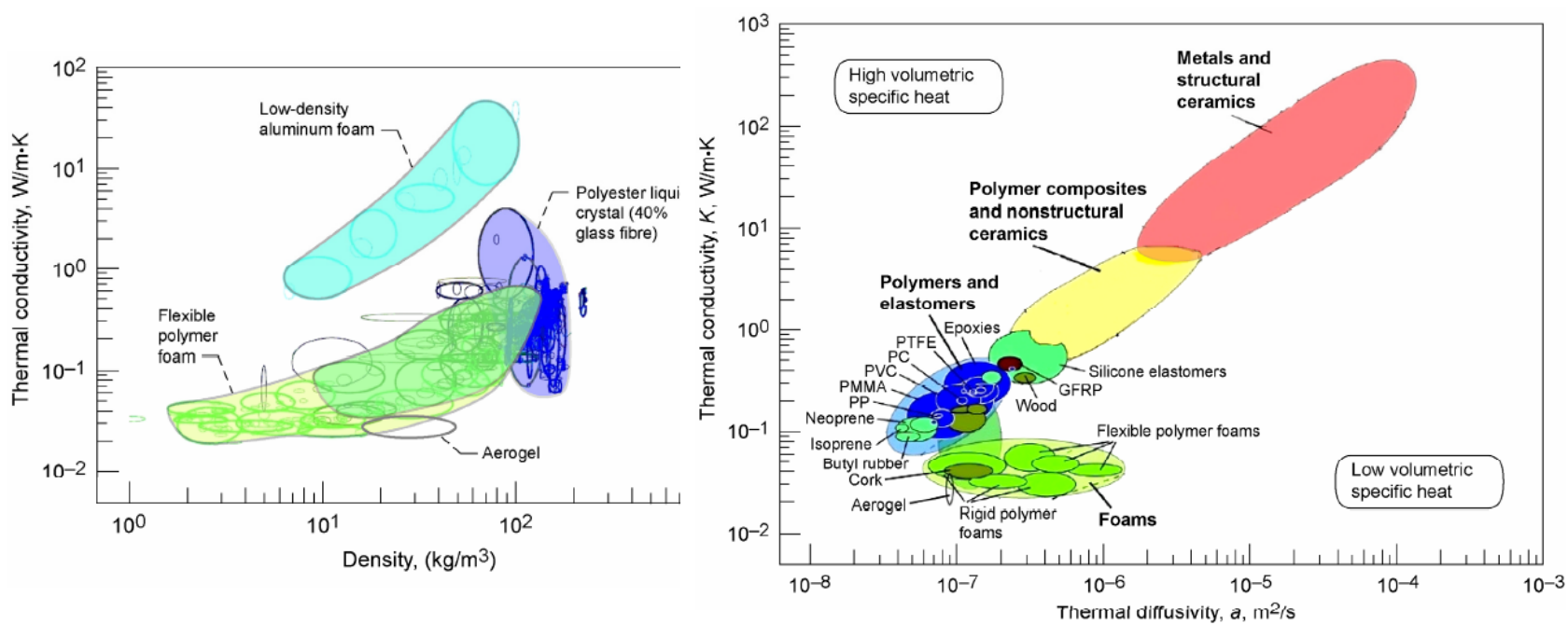

Figure 11: Thermal behaviour of different materials [5]

The aerogel is an open-celled, nanoporous, solid foam that is composed of a continuous 3-D network and the pores of the network are filled up by air. The aerogel exhibits a high porosity of more than $50 \%$. The nanostructure (nanopores and nanoparticles) provide the aerogel with outstanding properties. The 3-D solid backbone of the aerogels may be inorganic glass or ceramic, polymer (carbon), and hybrid materials. The aerogels contain particles and pores ranging from 2 to $50 \mathrm{~nm}$ in diameter.

The following advantages of aerogels exist for aerospace applications:

- Aerogel can excellently provide both thermal and acoustic insulation of a spacecraft. "Aerogel beads or granules in bulk-fill form could provide the thermal insulation for the liquid hydrogen tank $\left(\mathrm{LH}_{2}\right)$ intertank flange area."*

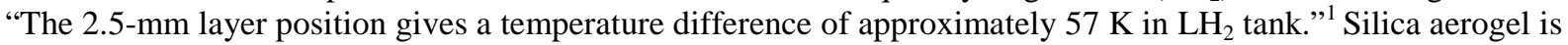
the best thermal insulator in the world. Its thermal conductivity (in air) is $0.03-0.004 \mathrm{~W} / \mathrm{mK}$. It almost blocks all the three types of heat transfer (convection, conduction, and radiation).

- Lightest solid materials, the silica aerogel is two thousand times less dense than a fused silica glass. Typical commercial silica aerogels have a density of $10-600 \mathrm{~kg} / \mathrm{m}^{3}$ and specific surface area of $400-1000 \mathrm{~m}^{2} / \mathrm{g}$.

- Good resistance to damage from space radiation and outgassing. The nanopore's structure of aerogels can capture high velocity particles without damaging them

The initial materials of the aerogel synthesis are generally metal alkoxides (e.g. $\left.\mathrm{Si}\left(\mathrm{OC}_{2} \mathrm{H}_{5}\right)_{4}\right)$. Sol-gel techniques are usually applied to produce aerogels. In the first step of the preparation, the alkoxides are subjected to react with water molecules (hydrolysis) and with each other (condensation) resulting in a continuous 3-D network (e.g. Si-O$\mathrm{Si}-\mathrm{O}-\mathrm{Si}$ ) (Figure 12). The pores of the network are filled up with solvents (e.g. ethyl alcohol). The second step of the synthesis is the drying of the wet gels. The drying can be performed under ambient pressure to produce compact xerogels. The other possibility for drying is the supercritical drying under supercritical pressure of a solvent. This solvent is generally supercritical or liquid $\mathrm{CO}_{2}$. By this way, the wet gel monoliths can be dried to aerogel monoliths without cracking and the aerogels keep the very unusual porous texture of the wet gel. The third drying method is freeze drying, which leads to formation of cryogels. The cryogels possess a high porosity but usually one lower than that of aerogels (Figure 12).

\footnotetext{
${ }^{*}$ Aerogel test in Cryogenics Test Laboratory at NASA’s Kennedy Space Center.
} 


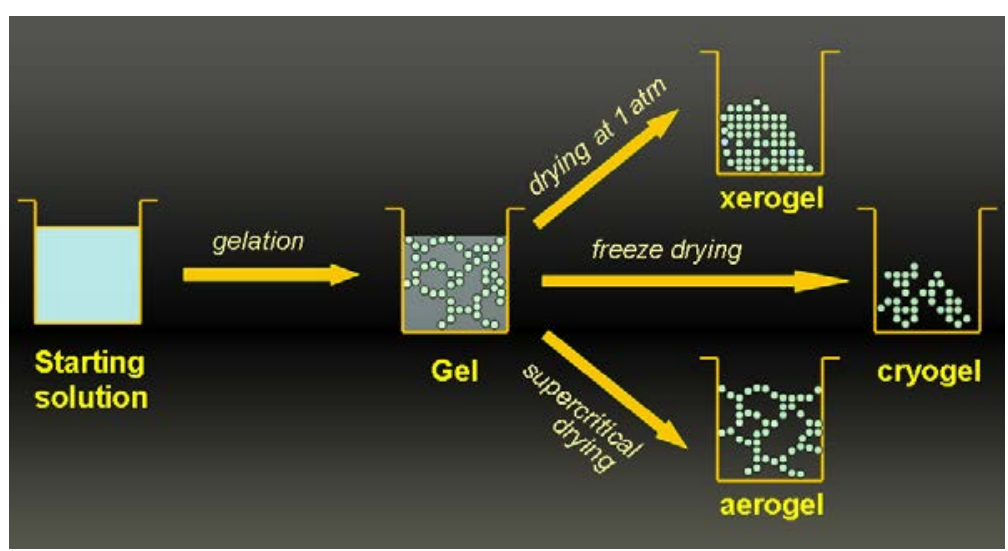

Figure 12: Outline of the sol-gel synthesis

One of the aims in CHATT is the assessment and comparison of the insulation materials, which are capable of insulating space objects. The other task is to investigate the temperature range of aerogel`s application. The samples are commercial aerogels (e.g. "Cabot", "Spaceloft") and aerogels prepared at ELTE. The high temperature limit has been determined by thermoanalysis and scanning electron microscope (SEM). The silica aerogels can be generally applied up to $600-650^{\circ} \mathrm{C}$, while the aluminosilicate aerogels up to $700-750^{\circ} \mathrm{C}$. For the determination of the low temperature limit, the samples are frozen by $\mathrm{LN}_{2}$. After freezing, the structures are checked by small and wide angle $\mathrm{X}$-ray scattering (SAXS and WAXS). The freezing at $-130^{\circ} \mathrm{C}$ did not affect any structural changes in the aerogel samples.

ELTE synthesized various porous materials, which are capable to insulating aerospace objects. Earlier ELTE had already produced aluminosilicate aerogels (specific surface area of $800-1000 \mathrm{~m}^{2} \mathrm{~g}^{-1}$ ). Currently, alumina cryogels are prepared because of the cheap initial materials and drying method. Moreover, the alumina possesses excellent chemical and heat resistances. Aluminium oxide even as a compact monolith is a good thermal insulator and is applied usually in the industry. The alumina aerogel is well known and published in several papers. But its procedure is expensive owing to the high price of precursors, Al-alkoxide and the time- and cost-consuming drying method. A new cheap and uncomplicated sol-gel method for alumina gel synthesis is developed at ELTE using only two initial materials, an inorganic Al salt and an alcoholic solvent. The cryogels can be characterized by macro- as well as micro-pores (Figure 13). The size of the macro-pores is about 100-200 $\mu \mathrm{m}$, the diameter of the micro-pores is approximately $20 \mathrm{~nm}$.

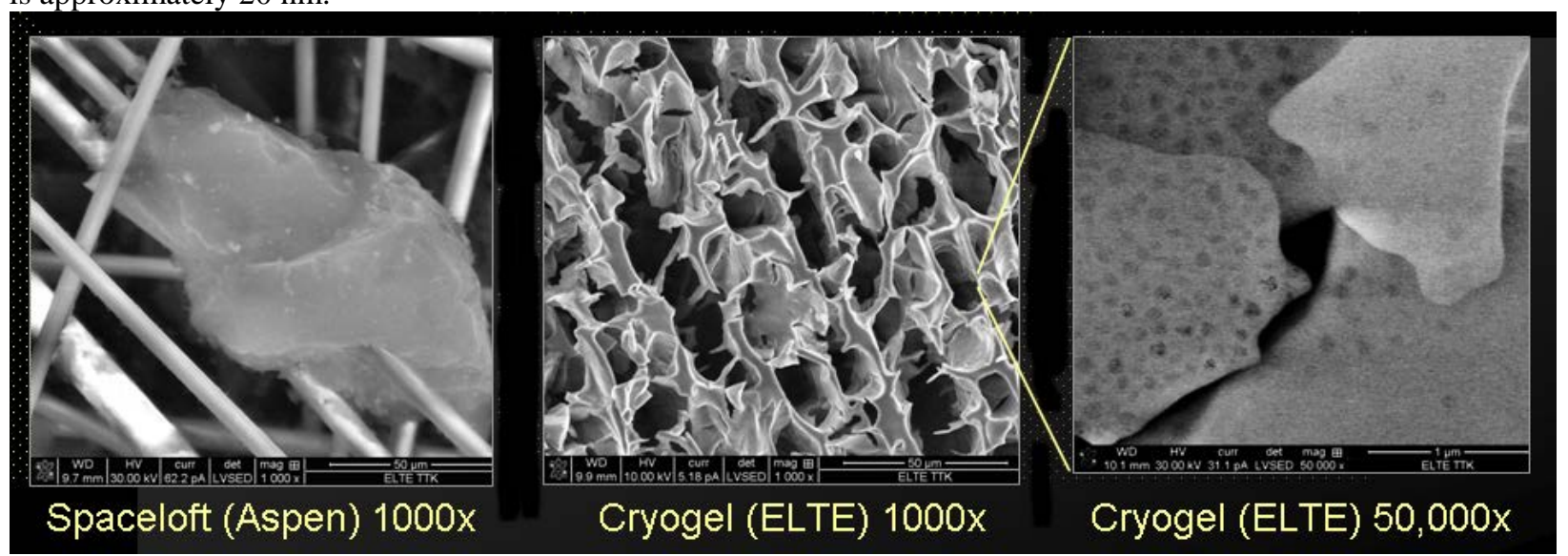

Figure 13: SEM images of aluminium oxide cryogel produced at ELTE and for comparison Spaceloft silica aerogel composite

\section{Conclusion}

The project CHATT is part of the European Commission's Seventh Framework Programme and run by DLR-SART in a multinational collaboration. The project started in January 2012 and is running for 42 months with a scheduled end in June 2015. The objectives of this effort with a total budget exceeding 4.2 M€ are to investigate different 
CFRP cryogenic pressure tanks, propellant crossfeed systems, advanced thermal insulation materials, and ceramic heat-exchangers. Four different subscale CFRP-tanks are planned to be designed, manufactured, and tested.

After approximately eight months some results from the research work are already available. The vehicle reference design loads and conditions have been defined for three reference vehicles representing three different concepts of hypersonic transportation vehicles. A literature review of CFRP tank design concepts and materials helped in the pre-selection of promising design options and materials for the demonstrator tanks. The aerogel is an open-celled, nanoporous, solid foam which could become an attractive insulation material for cryogenic tanks in the future. Supported by CHATT, a cost efficient production process is developed for alumina cryogels by ELTE.

\section{Acknowledgements}

This work was performed within the 'Cryogenic Hypersonic Advanced Tank Technologies' project investigating tank technologies for high-speed transport. CHATT, coordinated by DLR-SART, is supported by the EU within the 7th Framework Programme Theme 7 Transport, Contract no.: ACP1-GA-2011-285117. Further information on CHATT can be found on http://www.chatt.aero

The authors gratefully acknowledge the contributions of Tobias Schwanekamp, David Gerson, Matthias Bock, Shayan Sharifzadeh, Henk de Boer, Arjan Fraters, Jesper Eman, Andrejs Pupursand, and all other colleagues contributing to the CHATT research project.

\section{References}

1. NN: Grant agreement for: Collaborative project, Annex I - "Description of Work", Project acronym: CHATT, Project full title: "Cryogenic Hypersonic Advanced Tank Technologies", Grant agreement no: 285117, Version date: 2011-07-11, PART B

2. REL: http://www.reactionengines.co.uk/lapcat.html

3. Sippel, M.: Promising roadmap alternatives for the SpaceLiner, Acta Astronautica, Vol. 66, Iss. 11-12, (2010)

4. Sippel, M.; van Foreest, A.: SpaceLiner Rocket-Powered High-Speed Passenger Transportation Concept Evolving in FAST20XX, IAC-10-D2.4.06, 2010

5. S. K. Mital et al.: "Review of Current State of Art and Key Design Issues with Potential Solutions for Liquid Hydrogen Cryogenic Storage Tank Structures for Aircraft Applications”, NASA/TM —2006-214346. (2006)

6. Sippel, M.: Introducing the SpaceLiner Vision, $7^{\text {th }}$ International Symposium on Launcher Technologies, Barcelona, Spain, April 2-5, 2007

7. Sippel, M.; Schwanekamp, T.; Bauer, C.; Garbers, N.; van Foreest, A.; Tengzelius, U.; Lentsch, A.: Technical Maturation of the SpaceLiner Concept, AIAA-5850, 18th AIAA International Space Planes and Hypersonic Systems and Technologies Conference, Tours, September 2012

8. Sippel, M.; Votta, R.: Advanced Launcher Technology Maturation Supported by EU-Aeronautic Research Projects, IAC-12-D2.5.6, Naples, October 2012

9. Fraters, A.: Current state-of of-the-art knowledge in the structural aspects of advanced composite cryogenic tanks, Literature review of the state-of-the-art of topics relating to design, testing and production, CHATT Deliverable D3.1.1, 2012

10. Mattsson, D.: Report on specification, materials selection and theoretical design, CHATT Deliverable D3.2.1, 2012

11. Sinkó, K.; Sinclaire, J.; Temesi, O.: High porosity aluminium oxide systems, $10^{\text {th }}$ Colloid Chemistry Conference, Budapest (2012)

Further updated information concerning the SART space transportation concepts is available at: http://www.dlr.de/SART 